\title{
Reconstruction of surgical defect of the dorsum of the hand*
}

\author{
Maria Luiza Quintino Manna ${ }^{1}$ \\ Nicolle Canellas Camara Ajuz ${ }^{1}$
}

\author{
Juliana Lacerda Reis Ucelli ${ }^{1}$ \\ Felipe Maurício Soeiro Sampaio ${ }^{2}$
}

DOI: http:/ /dx.doi.org/10.1590/abd1806-4841.20175678

\begin{abstract}
In some cases, keratoacanthomas can be indistinguishable from squamous cell carcinoma, making the gold standard treatment surgical excision with histopathological evaluation. The surgical defects created on the back of the hand can be challenging to repair. We describe the use of bilateral rotation flap as an option in this area, and discuss the indications and contraindications of some of the possible surgical techniques for reconstruction of the dorsum of the hand.
\end{abstract}

Kewbords: Hand; Keratoacanthoma; Reconstruction; Surgical flaps

\section{INTRODUCTION}

Keratoacanthoma is a benign epithelial tumor that occurs predominantly on the face, but it can appear in any anatomic region. ${ }^{1,2}$ By having clinical and histopathological features sometimes indistinguishable from squamous cell carcinoma, the gold standard treatment is surgical excision with histopathological evaluation. ${ }^{3}$ When the surgical defects created after excision of skin tumors are located on the dorsum of the hands, they often present a reconstruction challenge. ${ }^{4}$ We describe the use of bilateral rotation flap as one of the options in this area.

\section{CASE REPORT}

A 68-year-old male patient presented with 2-month history of an enlarging nodular lesion with well-defined, smooth, erythematous border, and crateriform and keratotic center. The lesion measured $2 \mathrm{~cm}$ in diameter, was located on the back of his left hand, and was suggestive of keratoacanthoma. After complete excision, without safety surgical margins, the remaining defect measured approximately $2.0 \times 2.0 \mathrm{~cm}$ with partial exposure of the tendon of the extensor digitorum muscle (Figure 1). Histopathology confirmed the diagnosis of keratoacanthoma.

To repair the surgical defect, we opted for a bilateral rotation flap. Semicircles from the defect's medial distal edge to the radial and ulnar margins were designed for the planning (Figure 2). After local anesthesia, an incision was made following the pre-operative markings. The flap was undermined above the subcutaneous layer. It was necessary to create a Burow's triangle on the ulnar margin to facilitate tissue movement. Hemostasis was achieved with electrocoagulation. The flap lobules were positioned with a mononylon 3-0 suture in the medial point of the surgical defect and then

Work submitted on 02.07.2016

Approved by the Advisory Board and accepted for publication on 28.04.2016

* Work performed at the Dermatological Surgery Outpatient Clinic - Hospital Central do Exército

Financial Support: None.

Conflict of Interests: None.

Department of Tropical Dermatology of Hospital Central do Exército (HCE) - Rio de Janeiro (RJ), Brazil.

Dermatological Surgery Outpatient Clinic of the Department of Tropical Dermatology of Hospital Central do Exército (HCE) - Rio de Janeiro (RJ), Brazil. 
closed with mononylon 4-0 simple interrupted sutures (Figure 3). Excess skin of the proximal medial region of the surgical defect was excised, and borders were closed together.

It is important to emphasize that during surgery, the operated limb was kept in the greatest degree of extension (hand closed). In the immediate postoperative period, the patient was advised to rest and was prescribed topical petroleum jelly, pressure dressings and oral antibiotics. The sutures were removed in 14 and 21 days, with no complications (Figure 4 and 5).

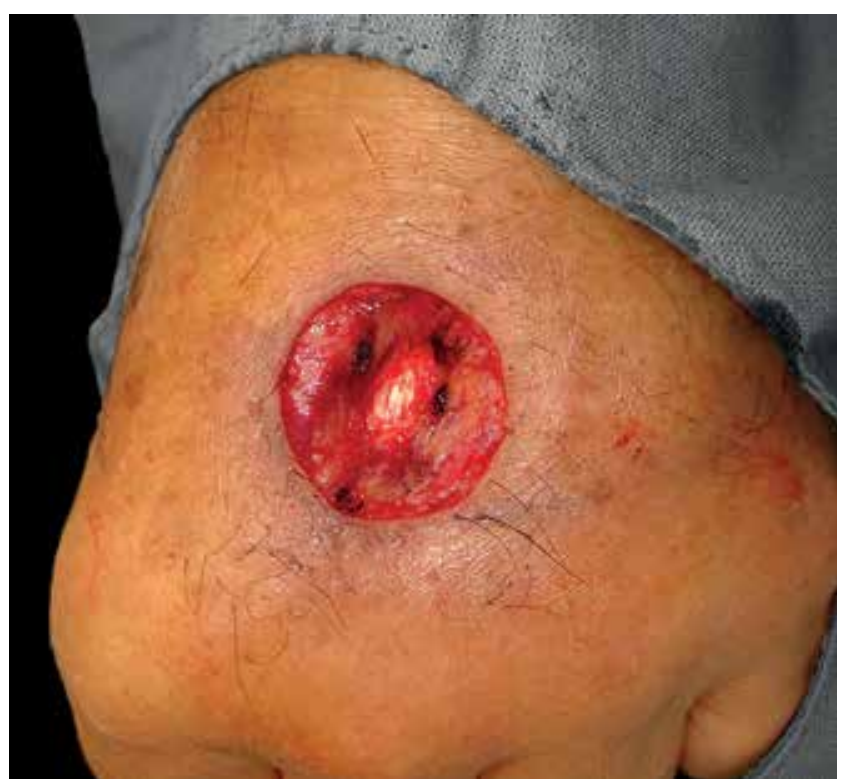

Figure 1: Surgical defect with partial exposure of the tendons of the extensor digitorum muscle

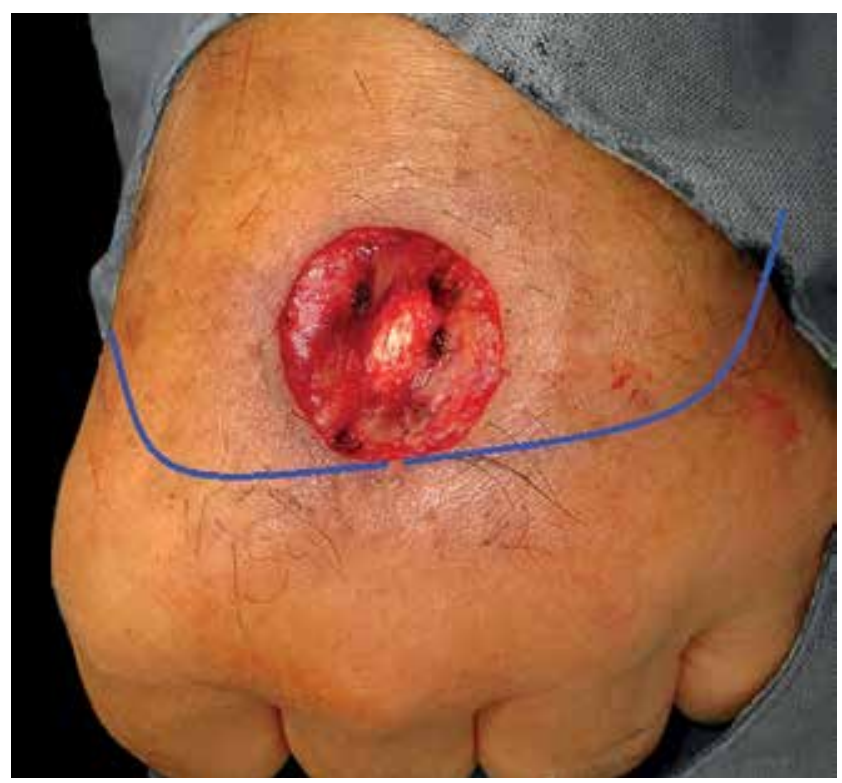

Figure 2: Semicircles marking from the distal medial edge of the defect towards the radial and ulnar edges

\section{DISCUSSION}

The hand plays essential roles in social function, expression, productivity and interaction with the environment. ${ }^{5}$ The skin in this area is flexible and allows for a wide range of motions. When faced with surgical defects in the hand, it is important to have knowledge of all possible reconstructive techniques, its advantages, disadvantages, limitations and complications to avoid disabilities. Perioperative considerations such as wound size, age, sex, occupation and medical comorbidities of the patient are also important when choosing the type of soft tissue cover. ${ }^{6}$

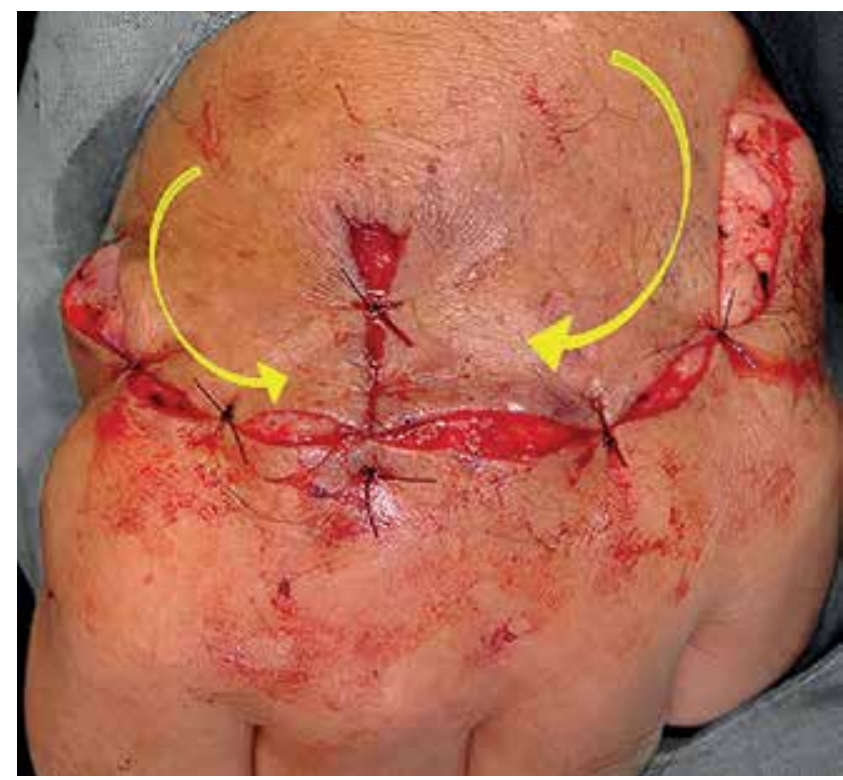

Figure 3: The flap lobules were positioned on the medial point of the surgical defect

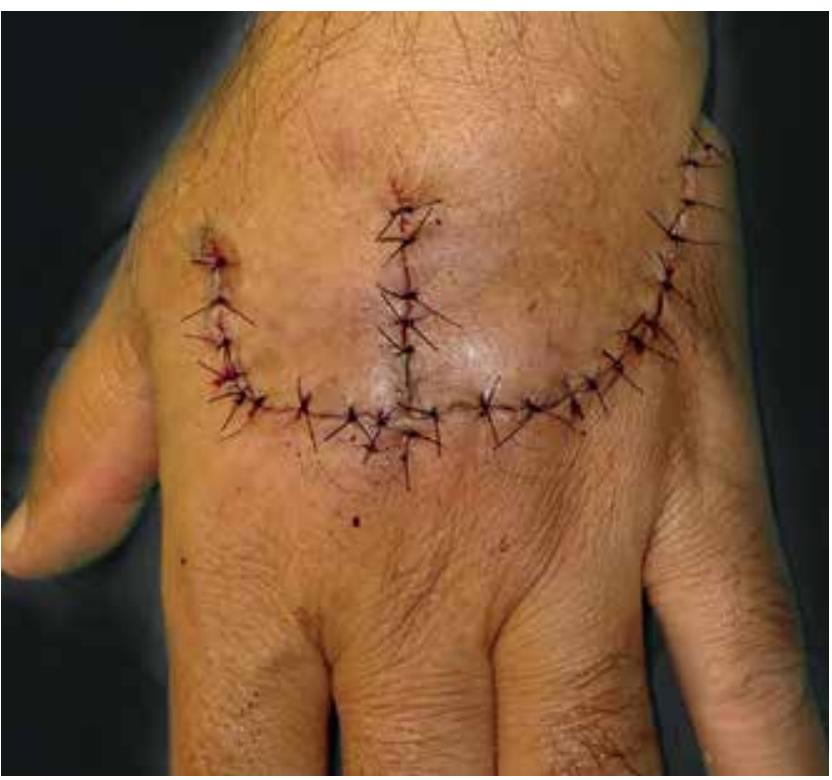

FIGURE 4: Sutures after surgery 


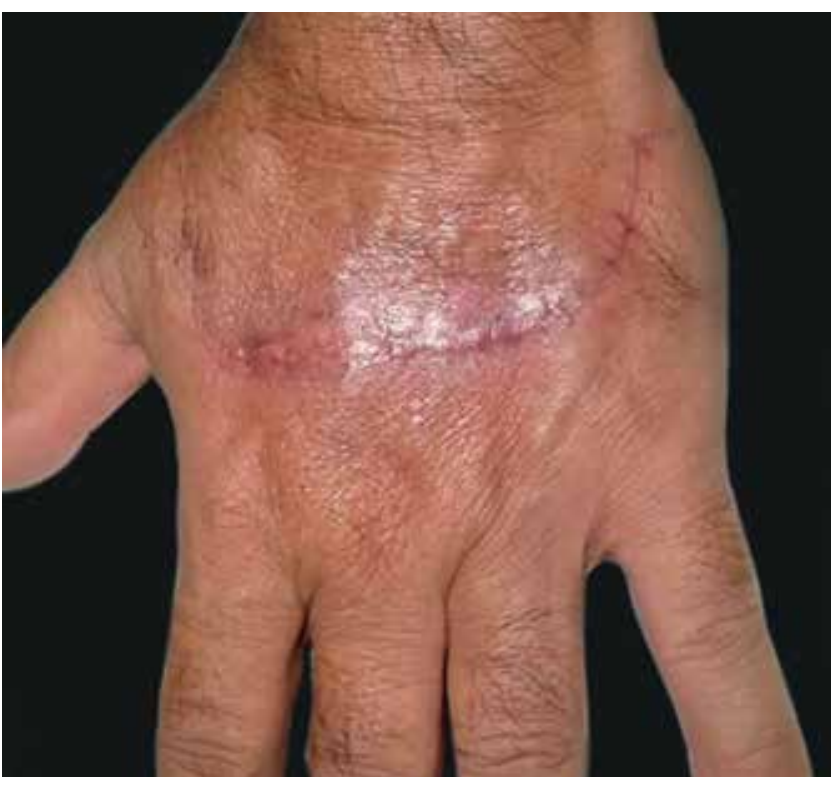

Figure 5: 21 days after surgery

Secondary intention healing is a reconstructive technique indicated for surgical defects located in concave areas and is the optimal choice for small defects. ${ }^{7}$ This method creates less trauma and reduces the time required for surgery. However, it may result in an unsightly scar, increased time for complete healing and higher risk of secondary bacterial infection..$^{8}$ Scar contracture can lead to a temporary or permanent disability of the hand.

Primary intention is indicated in the reconstruction of surgical defects located in anatomical areas that allow apposition of the edges without tension and subsequent lesser risk of necrosis. ${ }^{9}$ When appropriately applied, this technique maintains local function and aesthetics. Due to a lack of adequate volume of subcutaneous tissue in the dorsum of the hand, this technique is indicated only in the reconstruction of small defects, smaller than in our case.
When the surgical defect is big and cannot be repaired using primary closure or secondary intention, the use of a graft or cutaneous flap is preferred. ${ }^{6}$

Full-thickness skin graft is an option when the surgeon is unsure about the safety margins of a tumor or in cases for which flaps are not an option. However, to create a graft, a distant donor site is needed, which results in a second surgical wound, increases the time for the surgery and requires a higher volume of anesthesia. For aesthetic reasons and due to the possibility of limited flexibility, altered sensation and loss of cutaneous annexes, this method was not chosen in this case ${ }^{6}$.

Compared to a graft, a local cutaneous flap offers better color and texture, minimal tissue contraction, higher survival rate, lack of donor site scar and is appropriate when white fibrous tissue (tendon, bone and cartilage) exposure occurs. ${ }^{6,8}$ Rotation, advancement, and transposition cutaneous flaps are recommended for reconstruction of defects on the dorsum of the hand. ${ }^{6}$ The advancement flap could not be used in this case due to the size of the surgical defect. The vascular pedicle would not be sufficient to feed the distal edge of the flap properly, which would have increased the risk of necrosis.

The transposition flap was not chosen due to the size of the surgical defect and its location in the medial back hand. To be used in this case, advancement into a second anatomic area (e.g., the forearm) would be required and that could have compromised the aesthetic outcome.

In turn, the rotation flap has distinct advantages such as being a single-stage procedure, ensuring adequate blood flow through the pedicle, maintaining limb function and providing a satisfactory aesthetic result without extending into a second anatomic area. ${ }^{8}$ If unilateral, the rotation flap should be at least three or four times larger than the diameter of the defect, allowing adequate rotation of the flap for a closure without tension. ${ }^{6}$ In our case, as the defect was located in the medial back hand, a unilateral rotation would not have been adequate; therefore, a bilateral rotation technique was used.]

\section{REFERENCES}

1. Zargaran M, Baghaei F. A Clinical, Histopathological and Immunohistochemical Approach to the Bewildering Diagnosis of Keratoacanthoma. J Dent (Shiraz). 2014;15:91-7.

2. UpToDate.com [Internet] Brewer JD. Keratoacanthoma: Epidemiology, risk factors, and diagnosis. 2014 Jul [cited 2015 Jan 22]. Disponível em: http:// www.uptodate.com/contents/keratoacanthoma-epidemiology-risk-factors-anddiagnosis\#H5186444.

3. Thompson BJ, Ravits M, Silvers DN. Clinical Efficacy of Short Contact Topical 5-Fluorouracil in The Treatment of Keratoacanthomas: A Retrospective Analysis. J Clin Aesthet Dermatol. 2014;7:35-7.

4. Sampaio FMS, Miller MDB, Gualberto GV, Galhardo MCG, Valle ACF, Souza PRC Utilização do retalho bilobado na região pubiana após exérese de lesão tumoral. An Bras Dermatol. 2013;88:S226-8.

5. Hegge T, Henderson M, Amalfi A, Bueno RA, Neumeister MW. Scar contractures of the hand. Clin Plast Surg. 2011;38:591-606.

6. Rehim SA, Chung KC.Local flaps of the hand. Hand Clin. 2014;30:137-51, v

7. Glaich AS, Behroozan DS, Goldberg LH. Double rotation flap to repair two cheek defects in close proximity. Dermatol Surg. 2005;31:1717-9.

8. Biswas D, Wysocki RW, Fernandez JJ, Cohen MS. Local and regional flaps for hand coverage. J Hand Surg Am. 2014;39:992-1004.

9. Talbot SG, Athanasian EA, Cordeiro PG, Mehrara BJ. Soft tissue reconstruction following tumor resection in the hand. Hand Clin. 2004;20:vi, 181-202.

MAILING ADDRESS:

Felipe Maurício Soeiro Sampaio

Av. Nossa Senhora de Copacabana, 1059, sala 1003.

Copacabana -

22060-001-Rio de Janeiro - RJ -Brazil

E-mail:felipemauricio@uol.com.br

How to cite this article: Manna MLQ, Ucelli JLR, Ajuz NCC, Sampaio FMS. Reconstruction of defect of the hand dorsal site. An Bras Dermatol. 2017;92(5 Suppl 1):132-4. 